\title{
Effect of Government-Mediated Access Pricing on Availability of Directly Affected Drugs in Retail Drug Stores in the Philippines from 2009 to 2011
}

\author{
Jesus N. Sarol, Jr. ${ }^{1,2}$ \\ ${ }^{1}$ National Teacher Training Center for the Health Professions, University of the Philippines Manila \\ ${ }^{2}$ Rainiers Contract Research Services, Inc., M2 Strata Suites 300 P Guevarra St., San Juan City, 1500 Philippines
}

\begin{abstract}
Background. There is a scarcity of studies on the effects of government-mediated access pricing (GMAP) as another price regulation approach on drug availability.

Objectives. This study was done to compare changes in percent availability in drug stores from 2009 to 2011 of innovator drugs, competitor drugs and cheap generic drugs containing drug molecules affected by GMAP policies in the Philippines.
\end{abstract}

Methods. Data from a random survey of 600 drug stores stratified by location and retail type, undertaken separately in 2009 and 2011 by IMS Health Philippines, were analyzed. Percent availability of the innovator brand, a competitor, and cheapest generic version for 11 selected drug molecules in said drug stores were compared for 2009 and 2011.

Results. Of the 11 innovator drugs, 3 had significant reductions in percent availability in drugstores ranging from $9.7 \%$ to $39.0 \%$. Among competitor drugs, 3 had reductions ranging from $37.4 \%$ to $81.7 \%$. The availability of cheap generic versions of drug molecules in drug stores immensely increased in 2011 except for telmisartan.

Conclusion. GMAP could have adversely affected availability in drug stores of both innovator and competitor drugs. Cheaper generic drugs have become more available in the Philippines.

Key Words: drug industry, delivery of health care, government regulation, Philippines

Earlier version of paper was presented at the International Conference on Emerging Trends in Scientific Research, March 15-16, 2014, Pearl International Hotel, Kuala Lumpur, Malaysia.

Corresponding author: Jesus N. Sarol, Jr., PhD

National Teacher Training Center for the Health Professions

University of the Philippines Manila

3rd Flr. Dr. Joaquin Gonzales Hall

Padre Faura St.corner Ma. Orosa St., Ermita, Manila 1000, Philippines

Telephone: +632 5210899

Fax No: +632 5264259

Email: jnsarol1@up.edu.ph
Introduction

Availability and access to quality medicines form an important component of a country's health service delivery. Many major diseases are treated effectively with drugs. Access to cheap quality drugs continues to be a serious problem especially among the poor in developing countries. ${ }^{1}$ Low drug availability has been reported in the Philippines. ${ }^{2,3}$

Drug stores perform a critical role in providing access to drugs to the public. Ball and Tisocki provided an estimate of 30,000 retail outlets, of which $70 \%$ were private drug stores in 2008 in the Philippines. ${ }^{4}$ Citing the Pharmaceutical and Healthcare Association of the Philippines (PHAP) report in 2008, Ball and Tisocki further related that $80 \%$ of the pharmaceutical market was channeled through private chain and independent drug stores. ${ }^{4}$ Poor households spent substantial proportions of their income on out-of-pocket drug expenditures in the Philippines.5,6

The Philippines passed a law in 2008 known as "The Universally Accessible and Quality Medicines Act of 2008" and more popularly called the "Cheaper Medicines Act of 2008."7 This law empowered the government to regulate drug prices in order to achieve full effective competition in drug supply and demand, thus ensuring access to affordable quality drugs to its constituents. One of the most visible actions that the government has done in implementing this law is the enforcement of the maximum drug retail pricing (MDRP) and government-mediated access pricing (GMAP) policies for selected drugs. Under MDRP, the maximum price was set by the Philippine Department of Health (DOH) for drug products that carried five identified drug molecules. On the other hand, some drug companies voluntarily entered specific products for the GMAP listing wherein these products were to be sold at maximum reduced prices, usually at half of their current prices. Drug companies that distributed other drugs that carried the same molecule in the GMAP-listed drug are not required to sell their drugs at the volunteered reduced price. To effectively inform the public of these benefits, the government required drug stores to post the reduced prices of these MDRP/GMAP drugs on their premises.

The action of the Philippine government to impose MDRP and GMAP pricing constitutes a price regulation approach to control drug prices. Studies on price regulation have often looked into its effects on drug price and 
competition $^{8,9}$ and related outcomes such as drug use, healthcare utilization, health outcomes and expenditures, $8,9,10$ but rarely on drug availability. Danzon and Ketcham provide scant evidence that reference pricing reduces drug availability, in particular more expensive brands, in the case of New Zealand. ${ }^{11}$ Moreover, these studies concentrated on the effects of price cap ${ }^{8}$ and reference pricing approaches $s^{8,9,10}$ on price regulation but not on government mediation or negotiation approaches. Under price cap regulation, a maximum price value is set under which drug stores must sell all similar drugs. Reference pricing deals with maximum reimbursements for patients' drug expenses. Reimbursements for drug purchases are allowed only up to the stipulated reference prices for those drugs for treatment of their particular medical condition. As a mechanism for price regulation, government-mediated pricing, such as the one employed in the Philippines, works in a different way. Drug companies would offer to reduce prices of their drugs that are acceptable to the government. Other companies that distribute similar products are not required to comply with this voluntarily reduced price. However, price competition is anticipated with the consequential effect of bringing down drug prices.

Many countries in Europe also practice government price negotiation. ${ }^{12}$ However, the effect of this price regulation approach on drug availability has not been studied extensively. The effect on prices of directly affected drugs after implementation of MDRP and GMAP has been reported from the same study in another report. ${ }^{13}$ This study looked into the effect of government-mediated access pricing on drug availability in drug stores in the Philippines. Specifically, this study compared the change in availability in drug outlets of innovator brands, competitor brands, and generic versions of selected drug molecules affected by the government-mediated access pricing in 2011 using baseline levels in 2009. Differences in the trends of availability of these drugs across location and type of drug stores were also investigated. Large changes in the level of drug availability in retail stores that would occur in a considerable proportion, say greater than $25 \%$ of the concerned drugs, could be attributed to the effect of government mediated access pricing.

\section{Methods}

This study used secondary data from the IMS Health Philippines (IMS) surveys conducted in 2009 and 2011. IMS Health Philippines was commissioned by the Philippine Department of Health to conduct surveys during these years to monitor the prices and availability of drugs as part of the monitoring of the implementation of the Cheaper Medicines Act of 2008. The 2009 survey reflected baseline levels of drug price and availability while the 2011 survey was done to see changes in these indicators after the implementation of the law. The use of data from IMS was covered in a memorandum of agreement between IMS Health Philippines and Rainiers Contract Research Services Inc (RCRSI) to which the author is affiliated. Ethical approval was granted by the National Ethics Committee of the Philippine Council for Health Research and Development (PCHRD).

The procedures for the selection of drugs and drug stores were presented in greater detail in another publication. ${ }^{13}$ Briefly, a stratified sample of 600 drug stores was independently drawn by random sampling in 2009 and 2011 from the IMS Drugstore Distribution Database, a nationwide database of Philippine drug stores. Stratification was based on location and retail type. The resulting allocation of the sample by location and retail type is shown in Table 1.

Table 1. Distribution of drug stores according to location and retail type, by year

\begin{tabular}{ccccc}
\hline \multirow{2}{*}{ Location } & \multicolumn{2}{c}{$\mathbf{2 0 0 9}$} & \multicolumn{2}{c}{$\mathbf{2 0 1 1}$} \\
\cline { 2 - 5 } & Chain & Independent & Chain & Independent \\
\hline Metro Manila & 28 & 89 & 28 & 89 \\
Luzon & 34 & 232 & 34 & 232 \\
Visayas & 14 & 95 & 14 & 95 \\
Mindanao & 14 & 94 & 14 & 94 \\
Total & 90 & 510 & 90 & 510 \\
\hline
\end{tabular}

This study covered 11 drug molecules. These were included because data on drug price and availability were available for these molecules in both 2009 and 2011 IMS Health surveys. The criteria for selection of priority drug molecules in 2009 was based on a score obtained by consideration of the current sales value of molecules, the DOH morbidity and mortality data, Philippine Medical Data Index Prescription Counts and Philippine National Drug Formulary (PNDF) Classification. On the other hand, the 2011 survey covered only drug molecules that were carried by drugs in the government-mediated access pricing (GMAP) list. The intersection of the sets of drug molecules in both surveys resulted in the 11 drug molecules in this study.

After the selection of drug molecules, selection of stock keeping units (SKUs) was done. SKUs refer to the different drug brands that carry a specific drug molecule. For each molecule, three SKUs were selected as follows: 1) the most saleable brand; 2) the highest priced brand; and 3) the cheapest generic product in the sample drug store. Coincidentally, this resulted in the inclusion of the same innovator and competitor brands for each molecule in both 2009 and 2011 surveys. The cheapest generic brand varied according to what was available in the sample drug store during a particular visit. Thus, this study allowed direct comparison of the availability of innovator brands and competitor brands. The innovator and competitor drugs are listed in Table 2. The cheapest generic brand for each drug molecule is not identified in the table for obvious reasons. Comparison of results of drug availability of the cheapest 
generic brand with that of innovator and competitor brands should be done with caution. In effect, the presence of price and availability data for the cheapest generic drug indicated merely that the drug store was selling at least one cheap generic brand of each particular drug molecule under study. The data from the study did not allow determination of trends of availability of any particular cheap generic drug brand.

Data collectors acted as mystery buyers to obtain data on drug availability (and price) of the drugs in the list from the sample drug stores.

Table 2. List of innovator brand and competitor brands

\begin{tabular}{lll}
\hline \multicolumn{1}{c}{ Drug Molecule } & $\begin{array}{c}\text { Innovator } \\
\text { brand }\end{array}$ & $\begin{array}{c}\text { Competitor } \\
\text { brand }\end{array}$ \\
\hline $\begin{array}{l}\text { Amlodipine } 5 \mathrm{mg} \text { tablet } \\
\text { Losartan } 50 \mathrm{mg} \text { tablet } \\
\text { Losartan + Hydrochlorothiazide }\end{array}$ & $\begin{array}{l}\text { Norvasc } \\
\text { Cozaar }\end{array}$ & \multicolumn{1}{c}{ Asomex } \\
$50 \mathrm{mg}+12.5 \mathrm{mg}$ tablet & Hyzaar & Combizar \\
Telmisartan $40 \mathrm{mg}$ tablet & Micardis & Pritor \\
Atorvastatin $10 \mathrm{mg}$ tablet & Lipitor & Atopitar \\
Clopidrogel $75 \mathrm{mg}$ tablet & Plavix & Clopivaz \\
Gliclazide $80 \mathrm{mg}$ tablet & Diamicron & Clizid \\
Azithromycin $500 \mathrm{mg}$ tablet & Zithromax & Azyth \\
Ciprofloxacin $500 \mathrm{mg}$ tablet & Ciprobay & Zalvos \\
Metronidazole $500 \mathrm{mg}$ tablet & Flagyl & Patryl \\
Metronidazole $125 \mathrm{mg} / 5 \mathrm{ml}$ suspension & Flagyl & Patryl \\
\hline
\end{tabular}

The percentage of drug stores where each drug was available was obtained. Statistical significance of the changes in drug availability from 2009 to 2011 was assessed using Chi-square test or Fisher's exact test. The changes (or trends) in drug availability from 2009 to 2011 were also examined across locations (island groups - Metro Manila, Luzon, Visayas, and Mindanao) and by retail type of drug store (chain or independent). To assess the differences of changes in drug availability by location and type of drug store, a logistic regression model incorporating an interaction term of these variables with year was employed. The likelihood ratio test (LRT) comparing this model to a nested model without the interaction term was used to assess the statistical significance of the interaction. The odds ratios corresponding to the interaction terms were derived by getting the exponent of the estimates of the interaction term in the model.

Further details to illuminate the interactions are presented in tables only when the interaction effects for innovator and competitor drugs were significant. The $\alpha=0.05$ level of significance was used. The generic drugs were not brand-specific, that is, the cheapest generic brand was not the same across drug stores. This precluded meaningful interpretations of the interaction terms similar to that for innovator and competitor drugs. For obvious reasons, the interaction effects of location and type of drug store with year for the cheapest generic drugs are not shown in the tables.

STATA Ver 10.1 was used in generating the data analyses. ${ }^{14}$

\section{Results}

Table 3 shows the percent of drug stores that had the listed drugs at the time of visit in the 2009 and 2011 surveys. For the innovator drugs, there were significant reductions in the availability in drug stores of three drugs: Flagyl $125 \mathrm{mg} / 5$ $\mathrm{ml}$ suspension, Norvasc $5 \mathrm{mg}$ tablet, and Plavix $75 \mathrm{mg}$ tablet. Flagyl suspension had a percentage decrease of 39\% from $59.8 \%$ in 2009 to $36.5 \%$ in $2011\left(\chi^{2}=65.42, p<0.001\right)$. A $10 \%$ reduction in the percent availability of Norvasc $5 \mathrm{mg}$ tablet was seen, from $75.3 \%$ to $68.0 \%\left(\chi^{2}=7.95, p=0.005\right)$. The availability of Plavix tablet dropped to $46.2 \%$ in 2011 from $52.0 \%$ in $2009\left(\chi^{2}=4.09, \mathrm{p}=0.043\right)$. For the other innovator drugs, the changes in percent availability in drug stores were less than $7.5 \%$ and not statistically significant $\left(\chi^{2} \leq 0.93\right.$, $\mathrm{p} \geq 0.334$ ).

Table 3. Percent of drug stores where each particular innovator drug was available $(n=600)$

\begin{tabular}{lccccc}
\hline \multicolumn{1}{c}{ Innovator drug } & $\mathbf{2 0 0 9}$ & $\mathbf{2 0 1 1}$ & $\begin{array}{c}\text { Percent } \\
\text { change }\end{array}$ & $\begin{array}{c}\text { Chi- } \\
\text { square }\end{array}$ & $\begin{array}{c}\text { p- } \\
\text { value }\end{array}$ \\
\hline Norvasc 5 mg tablet & 75.3 & 68.0 & -9.7 & 7.945 & 0.005 \\
Cozaar 50 mg tablet & 43.5 & 41.2 & -5.3 & 0.669 & 0.413 \\
Hyzaar 50 mg/12 mg tablet & 36.7 & 34.0 & -7.4 & 0.934 & 0.334 \\
Micardis 40 mg tablet & 63.8 & 66.3 & 3.9 & 0.825 & 0.364 \\
Lipitor 10 mg tablet & 42.5 & 42.5 & 0.0 & 0.000 & 1.000 \\
Plavix 75 mg tablet & 52.0 & 46.2 & -11.2 & 4.085 & 0.043 \\
Diamicron 80 mg tablet & 71.2 & 71.3 & 0.0 & 0.004 & 0.949 \\
Zithromax 500 mg tablet & 46.5 & 48.7 & 4.7 & 0.565 & 0.452 \\
Ciprobay 500 mg tablet & 53.8 & 51.2 & -4.8 & 0.856 & 0.355 \\
Flagyl 500 mg tablet & 61.0 & 61.3 & 0.5 & 0.014 & 0.906 \\
Flagyl 125 mg/5ml & 59.8 & 36.5 & -39.0 & 65.421 & $<0.001$ \\
suspension & & & &
\end{tabular}

Among the competitor drugs, statistically significant reductions of greater than $30 \%$ in the availability of three drugs were recorded (Table 4). The availability of Clizid 80 mg tablet, which was $26.3 \%$ in 2009 , plummeted to $4.8 \%$ in $2011\left(\chi^{2}=105.42, \mathrm{p}<0.001\right)$. Asomex $5 \mathrm{mg}$ tablet had a $37.4 \%$ reduction in availability in drug stores $\left(\chi^{2}=12.11, \mathrm{p}=0.001\right)$ while Patryl $500 \mathrm{mg}$ tablet was found in $4.3 \%$ of drug stores, only half of its percent availability of $8.8 \%$ in 2009 ( $\chi^{2}=9.88$, $\mathrm{p}=0.002)$. On the other side, there was a significant increase in the percentage of drug stores that sold Combizar $50 \mathrm{mg} / 12$ mg tablet. From $59.5 \%$ in 2009 , this percentage rose to $70.0 \%$ in 2011, equivalent to $17.6 \%$ increase $\left(\chi^{2}=14.49, \mathrm{p}<0.001\right)$. Changes in drug availability in drug stores from 2009 to 2011 for the other competitor drugs were not significant $\left(\chi^{2} \leq 2.61\right.$, $\mathrm{p} \geq 0.106$ ). 
Table 7. Assessment of effect of interaction of year with location on drug availability of competitor drugs using logistic regression

\begin{tabular}{|c|c|c|c|c|c|}
\hline Competitor drug & $\begin{array}{c}\text { Int } \\
(\mathrm{OR})_{1}{ }^{1}\end{array}$ & $\begin{array}{c}\text { Int } \\
(\mathrm{OR})_{2}{ }^{1}\end{array}$ & $\begin{array}{c}\text { Int } \\
(\mathrm{OR})_{3}{ }^{1} \\
\end{array}$ & $\begin{array}{c}\text { Chi- } \\
\text { square }^{2}\end{array}$ & $\begin{array}{c}\text { p- } \\
\text { value }^{3}\end{array}$ \\
\hline Asomex $5 \mathrm{mg}$ tablet & 1.36 & 1.02 & 1.67 & 1.43 & 0.6982 \\
\hline Lifezar $50 \mathrm{mg}$ tablet & 0.29 & 0.50 & 0.45 & 13.23 & 0.0042 \\
\hline Combizar $50 \mathrm{mg} / 12 \mathrm{mg}$ tablet & 1.72 & 0.84 & 0.85 & 7.20 & 0.0659 \\
\hline Pritor $40 \mathrm{mg}$ tablet & 1.21 & 0.70 & 0.64 & 4.96 & 0.1748 \\
\hline Atopitar $10 \mathrm{mg}$ tablet & 0.15 & 0.50 & 0.52 & 3.99 & 0.2667 \\
\hline Clopivaz $75 \mathrm{mg}$ tablet & 0.91 & 0.37 & 0.79 & 6.29 & 0.0984 \\
\hline Clizid $80 \mathrm{mg}$ tablet & 1.83 & 2.99 & 2.45 & 1.94 & 0.5851 \\
\hline Azyth 500 mg tablet & 1.03 & 0.64 & 1.47 & 4.55 & 0.2081 \\
\hline Zalvos $500 \mathrm{mg}$ tablet & 0.86 & 0.55 & 0.45 & 1.43 & 0.6977 \\
\hline Patryl 500 mg tablet & 2.09 & 1.95 & 2.00 & 1.10 & 0.7780 \\
\hline $\begin{array}{l}\text { Patryl } 125 \mathrm{mg} / 5 \mathrm{ml} \\
\text { suspension }\end{array}$ & 6.93 & 44.21 & 2.68 & 10.39 & 0.0155 \\
\hline
\end{tabular}

${ }^{1}$ Int $(\mathrm{OR})=$ Interaction odds ratios. Three interaction terms are produced in the logistic regression with 4 levels of location (Metro Manila, Luzon, Visayas and Mindanao) and 2 levels of year (2009 and 2011). This column gives the exponential of the coefficient corresponding to each interaction term in the model. The interaction (OR) informs how much the odds ratio is multiplied when two indicator variables are both present (both coded as 1) as compared to when only one of them is present (one is coded 0 and the other coded as 1 ).

${ }^{2}$ Based on likelihood ratio test (LRT) comparing model with interaction and model without interaction.

${ }^{3} \mathrm{p}$-value corresponding to the LRT.

Further details of these interaction effects are shown in Table 8. The availability of Lifezar tablet in drug stores registered significant increases in Metro Manila $(59.8 \%$ in 2009 vs $78.6 \%$ in 2011, $\left.\chi^{2}=9.71, \mathrm{p}<0.0020\right)$. However, there was an apparent decrease in Luzon (72.6\% in 2009 vs. $65.4 \%$ in 2011, $\chi^{2}=3.17, \mathrm{p}=0.0752$ ), while no significant changes in Lifezar availability occurred in Visayas and Mindanao. The reduction in the availability of Patryl suspension in drug outlets was more severely felt in Metro Manila (6.8\% in 2009 vs. $0.9 \%$ in 2011 , Fisher's exact $\mathrm{p}=0.0180)$ and Visayas $(8.3 \%$ in 2009 vs. $2.8 \%$ in 2011, Fisher's exact $p=0.0670)$. No significant change was seen in Luzon (6.4\% in 2009 vs. $5.3 \%$ in 2011, $\left.\chi^{2}=0.31, \mathrm{p}=0.5790\right)$. From only one drug outlet $(0.9 \%)$ that had Patryl suspension in Mindanao, this reached five stores (4.6\%) (Fisher's exact $\mathrm{p}=0.0160)$. A significantly higher percentage of drug stores in Luzon carried Combizar tablet in $2011(75.2 \%)$ than in $2009(56.8 \%) \quad\left(\chi^{2}=20.11, \mathrm{p}<0.0001\right)$. However, this increase was not seen in other areas $\left(\chi^{2} \leq 1.17\right.$, $\mathrm{p} \geq 0.2800$ ).

Table 8. Percent availability of Lifezar $50 \mathrm{mg}$ tablet, Patryl $125 \mathrm{mg} / 5 \mathrm{ml}$ suspension and Combizar $50 \mathrm{mg} / 12 \mathrm{mg}$ tablet in drug stores in 2009 and 2011, by location

\begin{tabular}{|c|c|c|c|c|c|c|c|c|c|c|}
\hline \multirow[b]{2}{*}{ Location } & \multirow[b]{2}{*}{$\mathbf{N}$} & \multicolumn{3}{|c|}{ Lifezar $50 \mathrm{mg}$ tablet } & \multicolumn{3}{|c|}{ Patryl $125 \mathrm{mg} / 5 \mathrm{ml}$ suspension } & \multicolumn{3}{|c|}{ Combizar $50 \mathrm{mg} / 12 \mathrm{mg}$ tablet } \\
\hline & & 2009 & 2011 & $\begin{array}{c}\text { Chi-square / Fisher's } \\
\text { exact (p-value) }\end{array}$ & 2009 & 2011 & $\begin{array}{c}\text { Chi-square / Fisher's } \\
\text { exact (p-value) }\end{array}$ & 2009 & 2011 & $\begin{array}{c}\text { Chi-square / Fisher's } \\
\text { exact (p-value) }\end{array}$ \\
\hline Metro Manila & 117 & 59.8 & 78.6 & $9.7099(0.002)$ & 6.8 & 0.9 & $(0.018)$ & 41.0 & 34.2 & $1.1656(0.280)$ \\
\hline Luzon & 266 & 72.6 & 65.4 & $3.1715(0.075)$ & 6.4 & 5.3 & $0.3083(0.579)$ & 56.8 & 75.2 & $20.1056(<0.001)$ \\
\hline Visayas & 108 & 76.9 & 78.7 & $0.1071(0.743)$ & 8.3 & 2.8 & $(0.067)$ & 69.4 & 72.2 & $0.2017(0.653)$ \\
\hline Mindanao & 109 & 65.1 & 69.7 & $0.5222(0.470)$ & 0.9 & 4.6 & $(0.106)$ & 56.9 & 59.6 & $0.1698(0.680)$ \\
\hline
\end{tabular}

In terms of drug availability, differences between chain and independent drug stores are more pronounced than differences across location. With bigger capital investments, chain stores offer a much wider array of drug products than independent stores, thus the availability of drugs especially the commonly known branded ones is more likely to be higher in the former type of drug store. Thus, it would also be interesting to examine whether the effect of government mediation in drug pricing on drug availability would differ in chain and independent drug stores.

This study thus examined whether the changes in drug availability of the listed drugs from 2009 to 2011 differed by type of retail store. The trends of availability of innovator drugs from 2009 to 2011 differed significantly between chain and independent drug stores only for Flagyl $125 \mathrm{mg} / 5 \mathrm{ml}$ suspension $\left(\chi^{2}=4.86, \mathrm{p}=0.0275\right)$ and marginally for Lipitor 10 mg tablet $\left(\chi^{2}=3.48, \mathrm{p}=0.0619\right)$ and Hyzaar $50 \mathrm{mg} / 12$ tablet $\left(\chi^{2}=3.16, \mathrm{p}=0.0753\right)$ (Table 9$)$.

Table 9. Assessment of effect of interaction of year with type of drug store on drug availability of innovator drugs using logistic regression

\begin{tabular}{lccc}
\hline \multicolumn{1}{c}{ Innovator drug } & Int (OR) & Chi-square $^{\mathbf{2}}$ & p-value $^{3}$ \\
\hline Norvasc 5 mg tablet & 1.03 & 0.00 & 0.9718 \\
Cozaar 50 mg tablet & 1.30 & 0.26 & 0.6080 \\
Hyzaar 50 mg/12 mg tablet & 0.42 & 3.16 & 0.0753 \\
Micardis 40 mg tablet & 0.74 & 0.11 & 0.7437 \\
Lipitor 10 mg tablet & 0.36 & 3.48 & 0.0619 \\
Plavix 75 mg tablet & 0.92 & 0.02 & 0.8983 \\
Diamicron 80 mg tablet & 1.35 & 0.31 & 0.5769 \\
Zithromax 500 mg tablet & 0.45 & 2.07 & 0.1499 \\
Ciprobay 500 mg tablet & 0.99 & 0.00 & 0.9826 \\
Flagyl 500 mg tablet & 2.57 & 1.87 & 0.1718 \\
Flagyl 125 mg/5ml suspension & 2.94 & 4.86 & 0.0275 \\
\hline
\end{tabular}

${ }^{1}$ Odds ratio of the interaction term obtained by getting the exponential of the estimated coefficient corresponding to the interaction term in the logistic regression model. Only 1 interaction term is present in the model.

${ }^{2}$ Based on likelihood ratio test (LRT) comparing model with interaction and model without interaction.

${ }^{3}$ p-value corresponding to the LRT.

Table 10 shows the percent availability of Flagyl suspension, Lipitor tablet and Hyzaar tablet in 2009 and 2011 for chain and independent stores. Among the independent stores, the reduction in availability of Flagyl suspension was from $53.7 \%$ in 2009 to $30.8 \%$ in 2011 or a $42.6 \%$ decrease $\left(\chi^{2}=55.00, \mathrm{p}<0.001\right)$. In chain drug stores, a 
Table 10. Percent availability of Flagyl $125 \mathrm{mg} / 5 \mathrm{ml}$ suspension, Lipitor $10 \mathrm{mg}$ tablet and Hyzaar $50 \mathrm{mg} / 12 \mathrm{mg}$ tablet in drug stores in 2009 and 2011, by type of drug store

\begin{tabular}{|c|c|c|c|c|c|c|c|c|c|c|}
\hline \multirow[b]{2}{*}{ Type of drug store } & \multirow[b]{2}{*}{$\mathbf{n}$} & \multicolumn{3}{|c|}{ Flagyl $125 \mathrm{mg} / 5 \mathrm{ml}$ suspension } & \multicolumn{3}{|c|}{ Lipitor $10 \mathrm{mg}$ tablet } & \multicolumn{3}{|c|}{ Hyzaar $50 \mathrm{mg} / 12 \mathrm{mg}$ tablet } \\
\hline & & 2009 & 2011 & $\begin{array}{c}\text { Chi-square / Fisher's } \\
\text { exact (p-value) }\end{array}$ & 2009 & 2011 & $\begin{array}{c}\text { Chi-square / Fisher's } \\
\text { exact (p-value) }\end{array}$ & 2009 & 2011 & $\begin{array}{c}\text { Chi-square / Fisher's } \\
\text { exact (p-value) }\end{array}$ \\
\hline Chain & 90 & 94.4 & 68.9 & $19.6289(<0.001)$ & 86.7 & 94.4 & $3.1830(0.074)$ & 84.4 & 91.1 & $1.8642(0.172)$ \\
\hline Independent & 510 & 53.7 & 30.8 & $55.0021(<0.001)$ & 34.7 & 33.3 & $0.2140(0.644)$ & 28.2 & 23.9 & $2.4615(0.117)$ \\
\hline
\end{tabular}

big reduction was also seen from $94.4 \%$ in 2009 to $68.9 \%$ in $2011\left(\chi^{2}=19.63, \mathrm{p}<0.001\right)$, although in relative terms the percent reduction $(27.0 \%)$ was smaller than that for independent stores. A slight increase in Lipitor availability occurred among chain stores, $86.7 \%$ in 2009 vs. $94.4 \%$ in 2011 $\left(\chi^{2}=3.18, \mathrm{p}=0.074\right)$ while that for the independent stores had an insignificant decrease from $34.7 \%$ to $33.3 \% \quad\left(\chi^{2}=0.21\right.$, $\mathrm{p}=0.644)$. A similar pattern occurred for Hyzaar tablet although the changes in both types of drug stores did not reach statistical significance $\left(\chi^{2} \leq 2.46, \mathrm{p} \geq 0.117\right)$.

Among the competitor drugs, significant differences between types of drug stores in terms of trends of drug availability from 2009 to 2011 were seen for three drugs only: Patryl $500 \mathrm{mg}$ tablet $\left(\chi^{2}=9.18, \mathrm{p}=0.0024\right)$, Clizid $80 \mathrm{mg}$ tablet $\left(\chi^{2}=7.60, \mathrm{p}=0.0059\right)$, and Azyth $500 \mathrm{mg}$ tablet $\left(\chi^{2}=4.24\right.$, $\mathrm{p}=0.0394$ ) (Table 11). For the rest of the competitor drugs, aside from the non-significance of the interaction terms in the logistic regression model, the interaction odds ratios ranged in a limited interval from 0.39 to 2.72, further suggesting relatively small variation between types of drug stores in terms of differences of drug availability between 2009 and 2011 for these drugs.

Table 11. Assessment of effect of interaction of year with type of drug store on drug availability of competitor drugs using logistic regression

\begin{tabular}{lccc}
\hline \multicolumn{1}{c}{ Competitor drug } & Int (OR) & Chi-square $^{2}$ & p-value $^{3}$ \\
\hline Asomex $5 \mathrm{mg}$ tablet & 0.73 & 0.65 & 0.4196 \\
Lifezar $50 \mathrm{mg}$ tablet & 2.76 & 2.18 & 0.1401 \\
Combizar $50 \mathrm{mg} / 12 \mathrm{mg}$ tablet & 0.67 & 0.40 & 0.5253 \\
Pritor $40 \mathrm{mg}$ tablet & 0.36 & 1.72 & 0.1896 \\
Atopitar $10 \mathrm{mg}$ tablet & 1.32 & 0.15 & 0.7016 \\
Clopivaz $75 \mathrm{mg}$ tablet & 0.78 & 0.39 & 0.5330 \\
Clizid $80 \mathrm{mg}$ tablet & 3.78 & 7.60 & 0.0059 \\
Azyth $500 \mathrm{mg}$ tablet & 0.34 & 4.24 & 0.0394 \\
Zalvos $500 \mathrm{mg}$ tablet & 1.82 & 1.21 & 0.2723 \\
Patryl 500 mg tablet & 4.87 & 9.18 & 0.0024 \\
Patryl $125 \mathrm{mg} / 5 \mathrm{ml}$ suspension & 2.68 & 2.72 & 0.0988 \\
\hline${ }^{1}$ Odds ratio of the interaction term obtained by getting the exponential of the \\
$\quad$ estimated coefficient corresponding to the interaction term in the logistic \\
$\quad$ regression model. Only 1 interaction term is present in the model. \\
${ }^{2}$ Based on likelihood ratio test (LRT) comparing model with interaction and \\
$\quad$ model without interaction. \\
${ }^{3}$ p-value corresponding to the LRT.
\end{tabular}

Results showed a large reduction in Patryl $500 \mathrm{mg}$ tablet availability in chain drug stores from $37.8 \%$ in 2009 to $10.0 \%$ in 2011 (Table 12). This drug had very low availability in independent drug stores, only 3.3\% in both 2009 and 2011.
Sharp reduction in availability of Clizid $80 \mathrm{mg}$ tablet was observed in both chain $(80.0 \%$ in 2009 to $14.4 \%$ in 2011 ; $\left.\chi^{2}=77.60, \mathrm{p}<0.001\right)$ and independent drug stores $(16.9 \%$ in 2009 to $3.1 \%$ in 2011; $\left.\chi^{2}=53.38, p<0.001\right)$. The significant interaction effects for Patryl tablet and Clizid tablet could be attributed to the wide difference in baseline percent drug availability between chain and independent stores. There was a significant increment in percent of drug stores that sold Azyth $500 \mathrm{mg}$ tablet from $83.3 \%$ in 2009 to $94.4 \%$ in 2011 $\left(\chi^{2}=5.63, p=0.018\right)$ while only a small absolute increase from $27.1 \%$ in 2009 to $29.8 \%$ in 2011 , in percent availability of this drug occurred among independent drug stores.

\section{Discussion}

Broadly, the results showed that availability in drug stores of the majority of the innovator and competitor brands $(16 / 22=72.7 \%)$ were not negatively affected after implementation of the MDRP/GMAP policy. However, the availability of a considerable number of these drugs (6 of $22=27.3 \%$ ) declined substantially. The magnitudes of these reductions are considered non-random that could be attributed to the effect of government-mediated access pricing. On the other hand, availability of cheaper generic products in drug stores for all drug molecules in the list increased immensely in 2011, except for telmisartan whose patent has not expired in the Philippines.

The availability in drug outlets decreased significantly for innovator brands Flagyl $125 \mathrm{mg} / 5 \mathrm{ml}$ suspension, Norvasc $5 \mathrm{mg}$ tablet, and Plavix $75 \mathrm{mg}$ table, in spite of the half-price reduction by virtue of their inclusion in the MDRP/GMAP list. ${ }^{13}$ The reduction was largest for Flagyl suspension where the percent availability went down by $39 \%$. The availability of its competitor in the study, Patryl suspension, also recorded similar percentage reduction. However, the impact of this decrease is not comparable to Flagyl since Patryl only had $5.8 \%$ availability in drug stores while Flagyl had $59.8 \%$ in 2009 . The relative decrease in percent availability of Norvasc $5 \mathrm{mg}$ tablet was $9.7 \%$. The percent availability of its competitor drug, Asomex, declined by a much bigger magnitude of $37.4 \%$. The availability of Plavix tablet went down from $52.0 \%$ to $46.2 \%$. Its competitor, Clopivaz, registered an insignificant increase, from $24.7 \%$ in 2009 to $27.3 \%$ in 2011. Since these results indicate that competitors had not benefitted from the significant reductions of their innovator counterparts, the surge in availability of cheap generic versions of Flagyl, Norvasc, and 
Effect of Government-Mediated Access Pricing on Drug Availability

Table 12. Percent availability of Patryl $500 \mathrm{mg}$ tablet, Clizid $80 \mathrm{mg}$ tablet and Azyth $500 \mathrm{mg}$ tablet in drug stores in 2009 and 2011, by type of drug store

\begin{tabular}{|c|c|c|c|c|c|c|c|c|c|c|}
\hline \multirow[b]{2}{*}{ Type of drug store } & \multirow[b]{2}{*}{$\mathbf{n}$} & \multicolumn{3}{|c|}{ Patryl $500 \mathrm{mg}$ tablet } & \multicolumn{3}{|c|}{ Clizid $80 \mathrm{mg}$ tablet } & \multicolumn{3}{|c|}{ Azyth $500 \mathrm{mg}$ tablet } \\
\hline & & 2009 & 2011 & $\begin{array}{c}\text { Chi-square / Fisher's } \\
\text { exact (p-value) }\end{array}$ & 2009 & 2011 & $\begin{array}{c}\text { Chi-square / Fisher's } \\
\text { exact (p-value) }\end{array}$ & 2009 & 2011 & $\begin{array}{c}\text { Chi-square / Fisher's } \\
\text { exact (p-value) }\end{array}$ \\
\hline Chain & 90 & 37.8 & 10.0 & $19.0969(<0.001)$ & 80.0 & 14.4 & $77.5950(<0.001)$ & 83.3 & 94.4 & $5.6250(0.018)$ \\
\hline Independent & 510 & 3.3 & 3.3 & $0.1152(0.734)$ & 16.9 & 3.1 & $53.3769(<0.001)$ & 27.1 & 29.8 & $0.9444(0.331)$ \\
\hline
\end{tabular}

Plavix could likely be the significant factor for the decline in their availability. In 2009, only $15.3 \%$ carried generic versions of Flagyl. In 2011, the percentage of drug stores that carried at least one cheap generic version (33.8\%) had approached that of Flagyl (36.5\%). Similarly for Norvasc 5 $\mathrm{mg}$ tablet, the presence of generic counterparts in drugs stores increased by $282.4 \%$ in 2011 . The gap between the percent availability of Norvasc tablet and of having at least one generic version in 2011, $68.0 \%$ and $58.5 \%$, respectively, was much closer compared to the big difference in 2009 when it was $75.3 \%$ for Norvasc and $15.3 \%$ for a cheap generic version. The availability of generic versions of Plavix (clopidrogel) shot up to $24.2 \%$ in 2011 from only $3.7 \%$ in 2009, an increase of $554.1 \%$. Another explanation for the reduction of availability of the innovator drugs could be the effect of competition among the market leaders for these drug molecules. This, however, cannot be evaluated in this study. These surveys obtained the corresponding price and availability data from only one competitor brand for each innovator drug. The inclusion of any competitor brand in this study is due to either its being the most saleable drug or being the highest priced competitor, which did not necessarily mean it was the closest competitor of the innovator drug in terms of sales volume.

The results also suggest that when the price of a drug that is sold near or higher than the reference rate (in this case, the MDRP or GMAP price) is not appropriately adjusted downward, the availability of this drug in outlets will be adversely affected. This is illustrated by the case of Asomex $5 \mathrm{mg}$ tablet, Patryl $500 \mathrm{mg}$ tablet, and Clizid $80 \mathrm{mg}$ tablet. In the related article by the author, these were the only drugs that were sold at higher than MDRP/GMAP price in 2009 and did not reduce prices in $2011 .{ }^{13}$ The mean price for Asomex was around P26 in both 2009 and 2011. For Patryl tablet, mean price even went up by 53.2\%, from P10.2 in 2009 to P15.7 in 2011. Price of Clizid $80 \mathrm{mg}$ tablet remained at almost the same levels, P9.6 in 2009 and P9.1 in 2011. Interestingly, these drugs experienced the greatest reduction in availability in drug stores, 37.4\%, 51.1\%, and $81.7 \%$, respectively, for Asomex, Patryl and Clizid. These reductions were markedly higher than those experienced by innovator brands that were also adversely affected. It could be that distributors of these drugs had intentionally reduced their market supply, maybe due to non-profitability, or possibly even losses for them selling these drugs at the reduced prices. Another reason could be that drug stores were finding these brands moving slower at their noncompetitive prices and thus were less willing to procure them. These drugs were apparently not priced according to the principle of elasticity of consumer demand working as the primary market force on drug pricing. ${ }^{15}$ The case for Asomex being under MDRP policy yet sold at higher prices in 2011 has been noted as an odd exception and must be investigated. ${ }^{13}$ Still, it suffered the same consequences apparently due to its non-adjustment of price in accordance with the reference price.

An interesting result is the case of Flagyl $500 \mathrm{mg}$ tablet, the lone innovator drug that was not in the GMAP list. As commonly is the case for the innovator brands in this study, this was the most saleable drug among metronidazole 500 mg tablets. ${ }^{13}$ The drug Winthrop $500 \mathrm{mg}$ tablet was the brand under GMAP for this drug molecule. The price of Flagyl tablet did not change in $2011 .{ }^{13}$ In this study, there was no change in availability of Flagyl $500 \mathrm{mg}$ tablet in the drug outlets from 2009 to 2011 in spite of this resistance to price reduction. This single example, however, is not adequate to conclude that the availability of innovator drugs (and perhaps their major competitors) would be unaffected even with no price adjustment relative to the GMAP price if the manufacturer or distributor of the drug volunteered for GMAP listing is not a market leader. The other question of interest is "While the availability in drug stores of these drugs may not have been affected by the GMAP policy, what about their actual sales?" This question may be addressed to all drugs in this study.

Notwithstanding the acknowledged problem with interpreting this study's data on availability (and price) of the cheapest generic brand, there is evidently a rapidly growing market for the generic drug industry. Even if the actual data on the price of the cheapest generic drug is downgraded to being a mere indicator of the presence of at least one cheap generic brand of a particular drug molecule, the results suggest that the availability of cheap generic drugs in retail stores increased immensely for all drugs except telmisartan. A report by Frost and Sullivan in 2010 asserted that the generic drug market was small and accounted for only $19.6 \%$ in the Philippines. ${ }^{16}$ A more recent report stated that the generic drug sales in the country have grown significantly in the past years albeit still lagging behind branded medicines. ${ }^{17}$ Greater public awareness and acceptance of generic drugs could be behind these trends. Citing a Social Weather Stations survey reports, Picazo 
stated that generic drug use among Filipinos has increased. ${ }^{18}$ Another reason could be that the imposition of the MDRP/GMAP policy has made the more expensive leading brands less attractive for drug stores. With a ceiling on prices, drug stores may not mark up the prices of these already high-priced drugs for more profit. Ball and Tisocki reported that for generic drugs in the Philippines, mark-ups for retailers could range between $5 \%$ and $355 \%$. This would be naturally attractive for business. This might have driven drug stores to procure and sell more generic drugs where there could be better profit potential. In using price referencing as a strategy for price regulation, Galizzi et al. also reported that an increase in generic market share would result when the prices of branded drugs were not lowered to their reference values. ${ }^{9}$

Are specific cheap generic brands now attaining the status of market leaders? This study's results are limited in explaining the trends in availability of specific generic drug brands. The data collected from drug stores only determined the presence and price of the lowest generic drug regardless of its brand. Thus, the results are ambiguous as to whether specific generic brands' availability had increased or if these were a reflection of a growing number of new generic brands getting into the market.

The trends in drug availability, represented by the difference of the 2009 and 2011 percent availability levels, were compared across location and type of drug store. Variations in trends were assessed through testing of statistical significance of the interaction terms for location and type of drug store with year in a logistic regression model. Out of 22 tests performed for testing location and year interaction for innovator and competitor drugs combined, only two $(9.1 \%)$ were statistically significant at the $\alpha=0.05$ level. Testing for type of drug store and year interaction yielded four (18.2\%) statistically significant results in a similar number of tests. The values of the interaction odds ratios corroborated these. Most of the interaction odds fell with the interval 0.3 to $3.0(62 / 66=93.9 \%$ for location by year interaction and 20/22=90.9\% for type of drug store by year interaction). These results suggest that the trends of drug availability of innovator and competitor brands were generally similar across location and type of drug store. Further investigation of the observed statistically significant interactions pointed to baseline differences in drug availability, particularly that between chain and independent drug stores, as the factor that contributed to the statistical significance of these interactions. The examination of interaction effects did not lead to identifying any particularly consistent factor to account for the observed differences in trends.

There are limitations of the study that could have been addressed with additional information collected. In this study, the number of independent drug stores far outnumbered the chain drug stores, yet in terms of volume, the latter type of drug stores far outsold the independent stores. Actual sales and number of units sold of the listed brands in the drug stores were not collected. This data would have informed of the effects of GMAP on the market share of specific drug brands using total sales and number of units sold, and thus on the drug manufacturing and distribution industry.

\section{Conclusion}

This study showed that there were no statistically significant reductions in availability in drug stores for 16 of $22(72.7 \%)$ innovator and competitor drugs directly affected by the MDRP/GMAP policy implementation that were included in the study. The availability of six $(27.3 \%)$ innovator and competitor brands could have been adversely affected by MDRP/GMAP, with the latter brands experiencing more severe reductions than the former. For the innovator brands, the reductions in drug availability were associated with large increases in the availability of cheaper generic versions. The more negatively affected competitor brands were found to be those that did not reduce their drug prices in accordance with the GMAP prices. The availability of cheaper generic brands increased immensely in 2011, except in the case of telmisartan. There were no significant variations in the trends of prices of innovator and competitor drugs according to location and type of drug store, except for baseline differences that existed in 2009. A study looking into the sales and number of units of drugs sold and on a larger collection of drugs is recommended as this would provide additional information on the impact of government-mediated pricing on the drug industry.

\section{Acknowledgments}

This study is a part of a larger study evaluating the impact of the cheaper medicines law on the different stakeholders in the Philippines. Funding for this study is provided by a grant from the Department of Health/Philippine Council for Health Research and Development. The authors would like to thank IMS Health Philippines, particularly Mr. Sof Casuple, for facilitating the delivery of the data on the 2009 and 2011 IMS Health surveys and for providing additional information on the technical details of these surveys, and Ms. Regine Philline del Rosario for assistance in obtaining background information on the pharmaceutical industry in the Philippines. 


\section{References}

1. MDG Gap Task Force Report 2012. Millenium development goal 8: the global partnership for development - making rhetoric a reality. United Nations. 2012. pp. 61-63.

2. Cameron A, Ewen M, Ross-Degnan D, Ball D, Laing R. Medicine prices, availability and affordability in 36 developing and middle-income countries: a secondary analysis. Lancet. 2009; 373(9659):240-9.

3. Dichosa J. Establishment of a baseline for the performance indicators of the Health Sector Policy Support Programme Phase II - Final Report. Bureau of International Health and Cooperation. Philippine Department of Health. 2010. Unpublished.

4. Ball D, Tisocki K. Medicines Price Components in the Philippines, Health Action International Global [Online]. 2009 [cited 2014 Feb]. Available from http://www.haiweb.org/medicineprices/surveys/ 200807PHC/sdocs/PriceComponentsReportPhilippines.pdf

5. Batangan DB, Juban N, Philippines Pharmaceutical Situation: 2009 WHO Health Facility Survey on Medicines. World Health Organization/Department for International Development/Medicines Transparency Alliance [Online]. 2009 [cited 2014 Feb]. Available from http://www.medicinestransparency.org/fileadmin/uploads/Documents/c ountries/Baseline_Component_2_WHO_Surveys/Philippines_baseline_ Component_2_WHO_level_II_Household_Survey.pdf

6. Tobe M, Stickley A, del Rosario RB Jr, Shibuya K. Out-of-pocket medical expenses for inpatient care among beneficiaries of the National Health Insurance Program in the Philippines. Health Policy Plan. 2013; 28(5):536-48.

7. RA 9502. The Universally Accessible and Quality Medicines Act of 2008. Philippines.

8. Puig-Junoy J. Impact of European pharmaceutical price regulation on generic price competition: a review. Pharmacoeconomics. 2010; 28(8):649-63.
9. Galizzi MM, Ghislandi S, Miraldo M. Effects of reference pricing in pharmaceutical markets: a review. Pharmacoeconomics. 2011; 29(1):1733.

10. Aaserud M, Dahlgren AT, Kösters JP, Oxman AD, Ramsay C, Sturm H Pharmaceutical policies: effects of reference pricing, other pricing, and purchasing policies. Cochrane Database Syst Rev. 2006; (2):CD005979.

11. Danzon PM, Ketcham JD. Reference pricing of pharmaceuticals for Medicare: evidence from Germany, the Netherlands and New Zealand Front Health Policy Res. 2004; 7:1-54.

12. Kanavos P. Overview of pharmaceutical pricing and reimbursement regulation in Europe. London School of Economics Health and Social Care. 2001.

13. Sarol JN. Effect of government-mediated access pricing on price of directly affected drugs in the Philippines. 2014. Unpublished.

14. StataCorp. Stata Statistical Software: Release 10. College Station, TX: StataCorp LP. 2007.

15. Holt MA, International prescription drug cost containment strategies and suggestions for reform in the United States [Online]. [cited 2014 March]. Available from http://www.bc.edu/dam/files/schools/law/ lawreviews/journals/bciclr/26_2/07_TXT.htm

16. Frost and Sullivan, Generic drug market picks up steam in the Southeast Asian pharmaceuticals industry [Online]. 2010 [cited 2014 Feb] Available from http://www.frost.com/prod/servlet/press-release.pag? docid=217076527

17. Business Mirror, Generic drug sales in PHL lag behind branded medicines [Online]. 2013 [cited 2014 Mar]. Available from http://www.businessmirror.com.ph/index.php/en/news/economy/8152generic-drug-sales-in-phl-lag-behind-branded-medicines

18. Picazo OF, Review of the Cheaper Medicines Program of the Philippines. Philippine Institute for Development Studies [Online]. 2011 [cited 2013 Dec]. Available from http://www.dbm.gov.ph/wpcontent/OPCCB/fpb/b_DOH-CheaperMedicines/i-

Cheaper\%20Medicines\%20Program\%20Review.pdf 